\title{
Discovery of the 5.7-Year Douglass Cycle: A Pioneer's Quest for Solar Cycles in Tree-Ring Records
}

\author{
W.H. Berger ${ }^{*}$
}

Scripps Institution of Oceanography, University of California, San Diego, California, 92093-0244, USA

\begin{abstract}
The astronomer A.E. Douglass is generally recognized as the founding father of dendrochronology. He studied tree rings in the search for evidence that solar variation (as seen in sunspots) is reflected in climate variation. He was convinced that his quest was successful. Analysis of some of his early data using Fourier decomposition and comparison of tree-ring periodograms with those based on known solar cycles suggests that the cycles he found may not exist or may not be of pure solar origin. The findings here reported suggest a much stronger influence of tides on the tree-ring records than commonly considered. Douglass's great merit as the pioneer of tree-ring dating in archeology and tree-ring-based climatology remains unaffected by the findings here presented.
\end{abstract}

Keywords: Douglass, climate cycles, solar cycles, tree rings, Arizona.

\section{INTRODUCTION}

The astronomer A.E. Douglass (1867-1962), founding director of the Tree-Ring Laboratory of the University of Arizona (Fig. 1), is generally recognized as the first pioneer of dendrochronology [1-3]. His studies on the tree-ring records in the West provided a means for dating archeological remains well before the arrival of radiocarbon [4]. In the Southwest, many pioneering archeologists (Earl Morris, Emil Haury, and others) worked closely with Douglass to unravel the sequence of settlements and of building activities of ancient peoples.

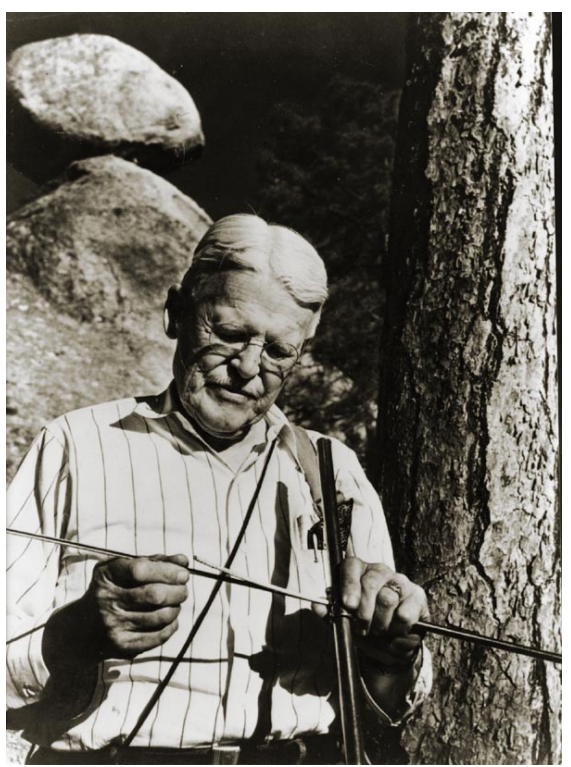

Fig. (1). A.E. Douglass inspecting a tree core extracted using an increment corer. (Source: University of Arizona, Laboratory of Tree-Ring Research. by permission).

\footnotetext{
*Address correspondence to this author at the Scripps Institution of Oceanography, University of California, San Diego, California, 920930244, USA; Tel: +858 755 6178; E-mail: wberger@ucsd.edu
}

Outstanding examples for these early efforts include the dating of the ruins of Chaco Canyon and Mesa Verde $\left(11^{\text {th }}\right.$ and $13^{\text {th }}$ century, respectively). Beyond the dating, tree-rings have offered evidence for long spells of drought in the West [5-7], periods that were of vital importance in the historical narratives of settlement and migration concerning the ancient civilizations. Quite generally, climate change as reconstructed from tree rings (and other sources) has become a central topic in the discussion of history [8-15]. More specifically, in the same context, tree-ring records are enormously useful in reconstructing stream-flow histories of the Colorado and other rivers in the West [16-20]. Most recently, climate history recorded in tree rings has become an important part of discussions about our climate future in the context of human impacts on the radiation balance of the planet [21-23].

Tree-ring dating was possible because for each given period of several decades in the past, in any one region, the sequence of tree-ring thickness describing the ambient climate at the time (especially the amount of precipitation [24]) is uniquely characteristic; that is, it has a bar-code quality. Once the code is familiar, based on the construction of a "master chronology," the relevant sequence can be fitted into the overall record at the correct position in time [25]. The procedure implies that sequences are not repeated. Thus, records cannot be dominated by a single cycle, or by several cycles in constant phase relationship.

While the methods introduced by Douglass are now in general use (with considerable modifications, both with respect to the information gathered from rings and with regard to statistics [26, 27]), the motivation for gathering tree-ring records is no longer central to such studies. Douglass, as an astronomer, was interested in the behavior of the sun through time, which he thought was reflected in climate change. Many of his publications emphasize the fact, and he reported prominently on the reconstruction of solar (sunspot) cycles from the climate cycles seen in tree growth records (which he linked to precipitation). Summaries of this work are in three volumes published by the Carnegie 
Institution [28-30], each of which bears the title "Climate Cycles and Tree-Growth."

The first of these publications has extensive tables in the Appendix, with tree-ring data. These data are the basis for the analyses here presented. The question is, to what extent can we verify Douglass's claim that solar information is ubiquitous in the climate narrative, using Douglass's own data. The matter is of some interest, given the fact that there is considerable discussion regarding the possible influence of the sun on climate [31-49].

Some very careful investigations yield results that put into doubt a general link of the 11-year solar cycle with climate change $[50,51]$. The issue here is not, however, whether such a general link exists or not. The issue here examined is, rather, whether the 11-year period is present in a few specific data records. It is certainly present, for example, in the sunspot record itself, and any attempt to refute such presence on the basis of arguments centered on statistical rigor would surely be futile. It is also present in the aurora record published by Schove [52], and in the ENSO history given in Quinn [53] (as shown below). It is also present, apparently, in some of the records provided by Douglass, but not in others. It may be present, in places, in the shape of a doubled sunspot cycle in drought sequences [54].

One of the cycles discovered by Douglass, and interpreted by him as evidence for solar forcing of tree growth, is a 5.7-year cycle first seen in his pine series from Flagstaff. This cycle, here referred to as "Douglass cycle" in what follows, yields 11.4 upon doubling, which Douglass considered close enough to the 11-year sunspot cycle to qualify as evidence that his quest was successful.

Instead of solar forcing, or in addition to such forcing, there seems to be a strong link into tidal activity in the treering records here analyzed, in agreement with assessments by Currie [55, 56] and by Cook et al. [41]. In fact, Cook et al. suggested the possibility of some kind of interference patterns between solar and tidal forcing, as did the great pioneer of climate history Lamb [10, p. 219]. A tidal connection, of course, would point to an influence of ocean oscillations in modulating climate history in the West, a possibility that has attracted much support [57-61]. Unfortunately, close to nothing is known about the forcing factors of ocean oscillations. In fact, judging from the lack of spectral analyses of such oscillations, there is little or no interest in deterministic elements within such oscillations in the oceanographic community (e.g., see Hurrell et al. [62] for a dearth of useful information in this regard, in an otherwise authoritative collection of articles on the North Atlantic Oscillation).

\section{SOLAR ACTIVITY CYCLES: WHAT ARE THE EXPECTATIONS?}

Ponderosa pine (Pinus ponderosa) and Giant Sequoia (Sequoiadendron giganteum) were favorite sources of information for Douglass's studies early in the $20^{\text {th }}$ century [28]. In addition, there were other conifers, from various parts of the world including Scandinavia and northern Germany. The goals of this work are clear from the subtitle to his first two major reports [28, 29]: "A study of the annual rings of trees in relation to climate and solar activity." In the third report, the subtitle simply declares: "A study of cycles," doing away with a reference to the concept of varying solar activity [30].

Before we consider the methods and results of Douglass, we should perhaps establish an expectation for what he should have found. There is no question that Douglass had such an expectation; that is, that a solar activity cycle near 11 years long would emerge from the study of records of tree growth, implying that the sun's variability is an important ingredient in the variation of precipitation in a number of regions in the northern hemisphere, especially in the Southwest and the West of the United States.

Whether this expectation was justified is still an open question. In their much-cited book entitled "The Role of the Sun in Climate Change," Hoyt and Schatten quote Sir Norman Lockyer as noting that looking for cycles is an attractive prospect. “ $\ldots$ if found, a cycle will help with predictions, and successful predictions are a central goal of scientific studies." [42]. However, the chapter where these encouraging words occur is entitled "Cyclomania," and the authors warn that "by feeding a stream of data into an algorithm to detect cycles, one is likely to find cycles even in a series of random numbers." They recommend keeping things simple [42, p. 165]: "If sophisticated analyses are required to detect the cycle, the cycle probably has only secondary importance."

Douglass employed sophisticated optical methods (a "periodograph" he invented) to detect cycles in the frequency domain, but he also used supremely simple methods: a direct comparison of tree-ring variation with sunspot cycles in the time domain. The methods here used to check on Douglass's results are anything but sophisticated by today's standards. I do use spectral analysis, a conceptual tool derived from the insights of Jean Baptiste Joseph Fourier $(1768-1830)$ early in the $19^{\text {th }}$ century (and one conspicuously missing in the discussion by Hoyt and Schatten). The computational effort is readily handled by a modern desk-top computer, but would have been out of bounds at the time Douglass did his research.

Recent work on the climate impact of solar variation suggests that Douglass's expectation (to find a link between climate and solar activity) was well justified. The same expectation motivates much modern work [45-49], albeit with mixed success. In a recent editorial in the journal "Climate Change," the climatologist Pittock urges the application of better statistics to the problem: "Clearly, in the case of sun-weather relationships, further research requires much higher standards of objectivity, with the rigorous and critical application of statistics, and step by step investigations of hypothetical mechanisms." [63, p.483] Pittock's comment well reflects prevailing skeptical attitudes toward any attempts to link solar variation with climate change.

Pittock's concern is understandable in view of the policy implications commonly associated with research into the relationships between solar activity and climate change, especially in regard to misled attempts to substitute solar forcing for anthropogenic greenhouse forcing [64, 65]. Surely, the rigor called for by Pittock is appropriate for editorial evaluation. It is not necessarily a path toward 
exploration and discovery. Above all, the "mechanism" part of his call has aspects of a red herring. No rigor is necessary to show that there is a solar activity oscillation near 11 years in length in the sunspot observations. Likewise, should similar oscillations emerge in a climate proxy record it would seem reasonable to link it to solar effects, whether the mechanism is known or not.

Douglass's search was for an observable phenomenon, and statistical rigor and mechanism were not at issue. Douglass (citing H. Schwabe) knew, from studies going back well into the $19^{\text {th }}$ century, that solar activity tends to be cyclic, with a period near 11 years, based on sunspot observations. Such data are readily available today on various web sites - the data here used are from the Royal Belgian Observatory (Fig. 2). From these data, it appears that the expectation should be that, if solar sunspot cycles impact climate, we should find periods close to 11.1 years in the climate record, or rather several periods varying between about 9.5 and 11.5 years, with a preponderance of periods of 11.1 and shorter.
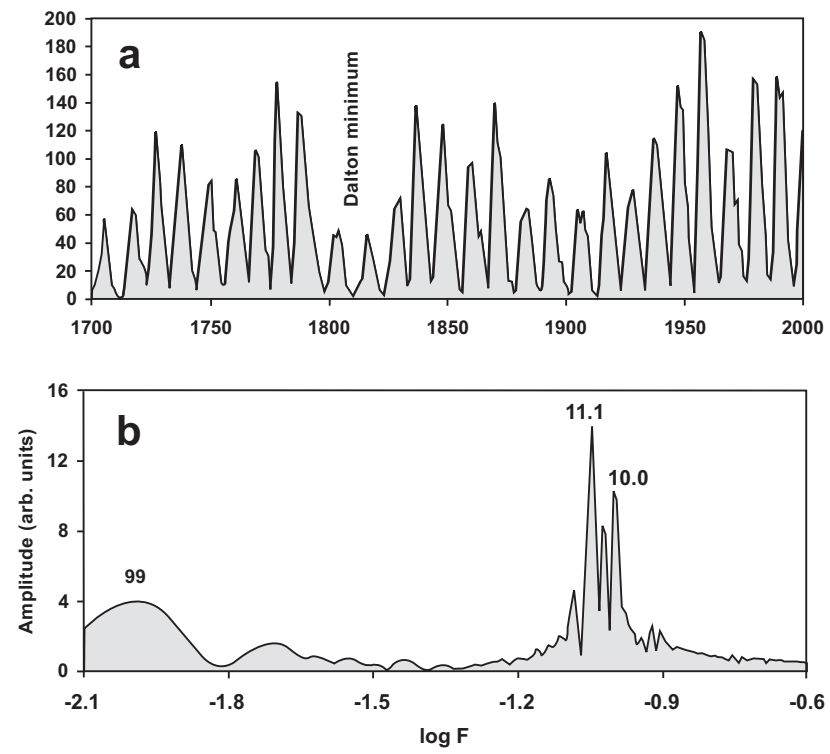

Fig. (2). Periodicity of the sunspot cycles between 1700 and 2000. Data source: Royal Astronomical Observatory of Belgium.

The well-defined solar activity periods emerging from a Fourier-type analysis of sunspot observations for the last 300 years are centered on 11.1, 10.5, and 10.0. The uncertainty in identifying the peak value is one percent (which is the resolution of the method here used: a stepped Fourier scan of the autocorrelation series). Thus, the peaks are at $11.1 \pm 0.1$, $10.5 \pm 0.1$, and $10.0 \pm 0.1$. Also, there is a long cycle near 100

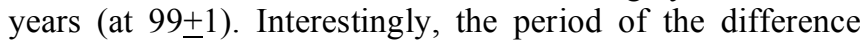
tone for the two dominant lines (11.1 and 10.0) is 100 years $[a * b /(a-b)]$. There seems to be no power in the periodogram of sunspots that would correspond to the so-called "Gleissberg" cycle at periods somewhere near 80 years in length [66]. The cycle is not present in the sunspot data, or else (if it exists) it merges with the 100-year cycle.

Douglass's study of a tree growth series in southern Sweden (Fig. 3) confirms the expectation of a period near 11 years in duration. Douglass corrected the measured ring series for a systematic decrease in width through time, both by subtracting the trend from the data, and by standardizing the variation from the trend - the argument being that when rings are narrow they have less room for variation than when they are wide. After standardization and some smoothing of the record, cycles of the sought-after length (near 11 years) emerged. There are seven such cycles shown in Douglass's graph for the time span between 1831 and 1906; that is, for 75 years.

The corresponding average length of the cycles is 10.7 years, which happens to be the sunspot period for much of the $20^{\text {th }}$ century. For the late $19^{\text {th }}$ century, slightly longer periods would be appropriate but the difference would be difficult to see in Douglass's graph. The overall coincidence of phase of sunspots and ring width is remarkable in these data, suggesting that a slightly brighter sun (more sunspots) enhanced tree growth in the circumstances studied in this example (as pointed out by Douglass).

\section{CORRELATION WITH SUNSPOTS.}

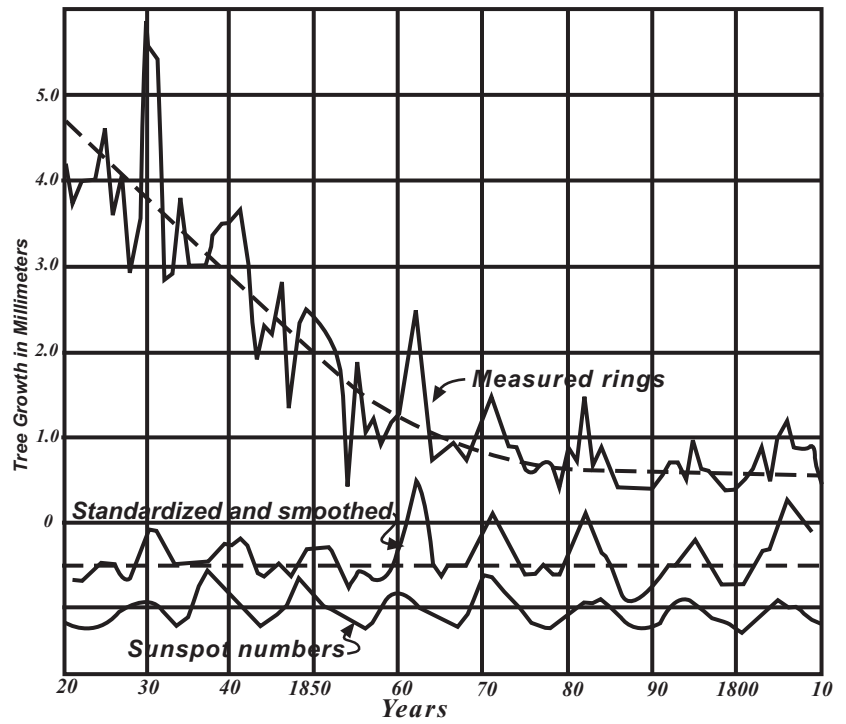

Fig. (3). Douglass's comparison of slightly smoothed tree-growth cycles with sunspot numbers. Source: Douglass [28].

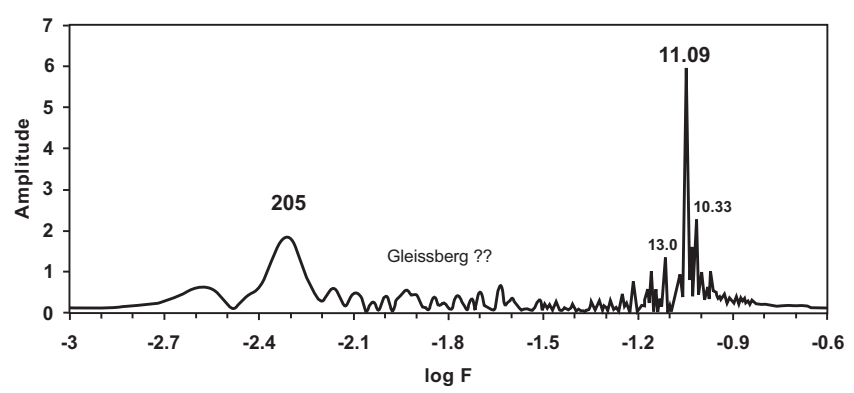

Fig. (4). Periodogram of aurora observations compiled by Schove [52], for the past 14 centuries.

In addition to relatively short records (for calibration of tree rings with precipitation), Douglass [28] obtained records two thousand years long, from the stumps of Giant Sequoia trees in the Sierra Nevada in California. To get an independent estimate of the length of solar activity periods for that interval, I analyzed the aurora data of Schove [52], 
which go back some 1400 years. As do sunspots, these data directly record the activity of the Sun, rather than representing some kind of proxy filtered by natural recording devices. These data also suggest an overall cycle length for solar activity near 11.1 years. The peak is quite sharp, suggesting that the variations of solar activity, while including a broad band of frequencies, tend to converge on a well-defined period during the last millennium. This fixes expectations quite reliably. In addition there is some power near 200 years, but none near 100 and none within the "Gleissberg" range, around 80 years.

\section{EARLY WORK AND FINDINGS: DOUGLASS 1919}

Armed with the expectation for a cycle of length 11.1, we can now turn to the records presented by Douglass in 1919 [28].

Regarding the 11-year cycle in his tree-ring data, Douglass [28, p.101] comments as follows:

"Only two tree records, the yellow pine and the sequoia, extend back of the first telescopic observations of sunspots. It is of peculiar interest to see whether the trees which carry the rainfall record back so far with a comparatively high degree of accuracy show the same cycle. In nearly all parts of the yellow-pine curve there are suggestions of an 11-year cycle. By tracing this throughout the record, the period is found to have a length of about 11.4 years, which is sufficiently close to the length of the sunspot cycle to be considered identical with it. This exact figure is not yet considered final, as future intensive study of the short-period variations in the trees may throw more light upon it. Taking 11.4 years as the probable length, the average total variation is found to be some 16 per cent of the mean growth. The period is generally doublecrested with two well-developed maxima and minima, but they are rarely symmetrical. During the 120 years from 1410 to 1530 it shows most remarkable regularity. ...This bit of record in the yellow pines and the 90 years of record in the wet-climate Scotch pines near the Baltic Sea give the finest examples of rhythmic growth yet found in the trees".

Douglass gives the Latin name of the "yellow pine" as $P$. ponderosa elsewhere in the text. The Flagstaff series is based on adding measurements of between two and nineteen trees (with the greater number in later years). He reports a cycle of length 11.4 years, which he considers a "double-crested" representation of the solar cycle. His report rests on the finding a 5.7-year cycle, and his interpretation of this cycle as of solar origin. Next, I verify that the 5.7-year Douglass cycle is indeed present within the "yellow pine" record (referred to as "Flagstaff" record in what follows) and that the 11.4-year cycle is not.

The relevant periodogram (Fig. 5, lower panel) in fact shows the 5.7-year Douglass cycle dominant at 4 standard deviations $(\mathrm{p}<1 \%)$. This confirms the presence of the cycle that Douglass discovered and reported. His interpretation of this cycle as a harmonic of solar activity is not denied or confirmed by the analysis. We simply note that within the band of solar frequencies, power does not rise noticeably above the general noise level. It seems that a period of length 11.4 is an unlikely candidate for solar origin in any case (Figs. 2, 4). If there are solar harmonics present in the series under discussion, 20.8 and 5.3 are the better candidates. They would point to periods of 10.4 and 10.6, respectively, periods that are central within the solar activity band for the last 300 years (Fig. 2).

Regarding the prominent line near 23.7 ( $\mathrm{p}<6.5 \%$ ), it is interesting that it is identical to the difference tone expected from interactions of a tidal 18.61 (nodal) cycle and a solar cycle of 10.43. Regarding the period of 75 seen in the periodogram $(\mathrm{p}<8 \%)$, it is expected from an interaction between the 5.7-year cycle and the 5.3-year cycle $(\mathrm{a} * \mathrm{~b} /(\mathrm{a}-$ b)).
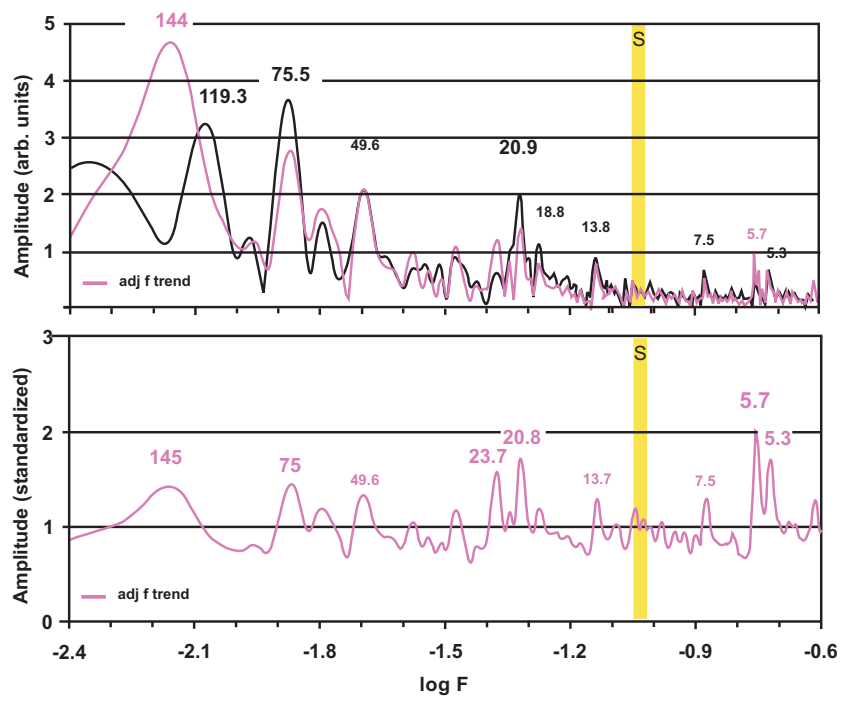

Fig. (5). Periodograms for the 500-year pine record near Flagstaff in Douglass [28] (Appendix, 1392-1906). Upper: black line, raw growth data; magenta, series adjusted for trend, including recalculation of local amplitudes of variation. Lower: additional recalculation of the adjusted periodogram in terms of mean and standard deviation within a gliding window of a factor of three. The mean is set at unity, the stdev. at 0.25 .

Thus, if we were to give meaning to the five dominant periods in the Flagstaff data in terms of solar cycles and deterministic forcing, we should be obliged to consider a solar cycle of 10.5 years, and the possibility of interference between tides and solar activity (as contemplated by Cook et al. [41] and by Lamb [10]). Also, we should have to admit interference between shorter periods resulting in the transfer of power to longer ones. These concepts imply a "family" of cycles related to each other through both multiples and interference. (Douglass considered multiples only.) Alternatively, we could persist in treating the spectra of periods solely as the product of some kind of chaotic activity. In either case, the Douglass cycle at 5.7 years would be unexplained. I suggest it is close enough to the tidal line at 5.8 (interference line between nodal and perigee tide) to warrant suspecting a link to the tides. One might consider (with a nod to Douglass's preference) that a shortening from 5.8 to 5.7 might be favored by an attempt of the system to 
reflect solar-cycle variation at a one-half period harmonic (near 5.5).

I should point out that, regarding the precision of the numbers discussed in the tree-ring series, Douglass was very aware of (and concerned with) uncertainties introduced from the absence of rings or the presence of double rings. Based on his assessment of the problem, I suggest an error band of $1 \%$. This error band and the one for the analysis $(1 \%)$ are additive, meaning that a tree-ring-derived cycle here placed at 10.5 , for example, should be read as $10.5 \pm 0.2$.

We next turn to the impressive multi-millennial record that Douglass obtained from the study of Giant Sequoia tree stumps, in California [28, Appendix]). Using his ingenious optical periodograph method, Douglass found as follows [28, p. 100]:

"The sequoias ... experience the heavy precipitation of the temperate-zone winter combined with dry-climate summer conditions ... The tree-growth shows a relation to the rainfall in the great valley below and therefore we could expect some similarity to the Arizona pines. This does exist, but the exact 11.4-year cycle shown in the pines is less evident in the sequoias, though unmistakably there. The analysis of the long sequoia record will be shown below. In it several cycles between 7 and 15 years predominate in places. The 11year period is plainly evident through most of the record and for some centuries is the predominant cycle, but for long periods other slightly differing cycles, such as 10 years, 12.6 years, or 13 years, are more evident. It is as yet impossible to say whether at these times there was a real change in the sunspot period, whether some subordinate period is operating in the sun, or whether only local conditions of some kind are the controlling factor".

Based on the analysis here offered (Fig. 6), the statement that the 11.4-year cycle is "unmistakably there" is not supported by the data gathered by Douglass. However, a 12.6-year period might be construed from a line at 6.3, invoking a Douglass-type "double crest." Also, there is power between 37 and 38 (labeled "Bru" in the graph) and near a 100-year period (labeled “ 100"). Douglass emphasized the presence of the 100 -year period, placing it at 101. The label "Bru" refers to the Brückner cycle, invoked a number of times by Douglass. Eduard Brückner (18621927), a pioneer climatologist, proposed a pervasive centuries-long 35-year climate cycle over much of Europe, in the 1890s [67].

Douglass [28, p. 101] thought that the Flagstaff series and the Sequoia series agreed in showing a period of about 100 years, but also pointed out that the Flagstaff period is closer to 120 years than to 100 . With 500 years in the analysis, a discrepancy of 20 percent seems too large to explain away arguing for lack of precision. In other words, the two cycles are not the same.

Douglass provided data back to 284 B.C. for the " 1915 " group of Sequoia trees. I am using here the data since 550 A.D., as being both highly reliable and close enough to be strongly linked to the known qualities of solar variation (as represented in Figs. 2, 4). It is well to appreciate the enormous amount of work contained in these Sequoia records. Douglass $[28$, p. 56] reports as follows:

"In the first work on the 2,200-year sequoia record, the identification [of rings] was a laborious task involving all the writer's spare time for a year."

The implication is, surely, that re-analysis of such rare and valuable data is a worthwhile endeavor (Fig. 6).
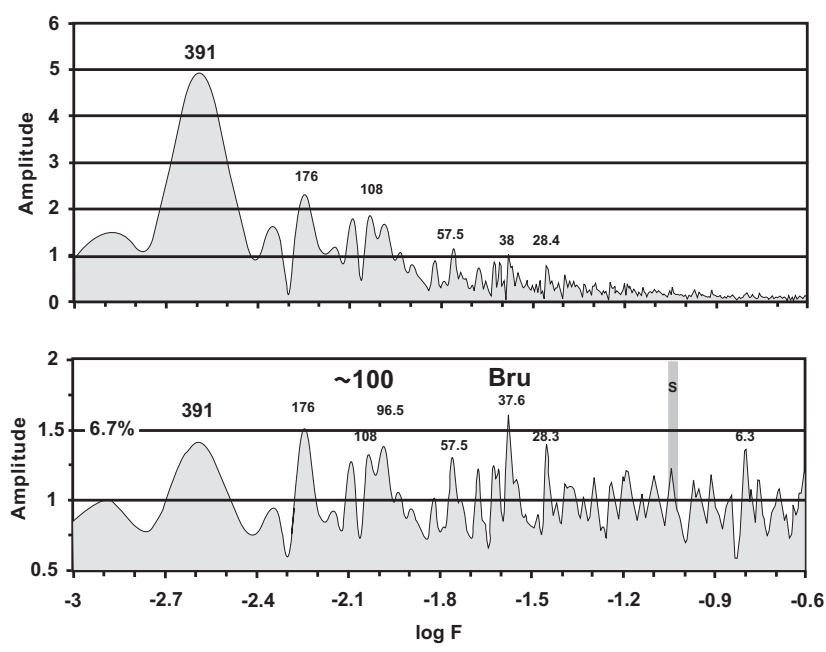

Fig. (6). Periodograms of the tree-ring series of Giant Sequoia, California, as given in Douglass [28], from AD 550. Upper: adjusted growth data, eliminating overall trend; lower: re-calculated periodogram, with standardized variation for a gliding window along $\log \mathrm{F}$ of length factor-of-three. The mean is set at unity, and the standard deviation at 0.25 . Two standard deviations (at 1.5) are equivalent to $\mathrm{p}=6.7 \%$. "Bru," Brückner cycle.

The chief problem emerging from the analysis of the Sequoia series is that there is no evidence whatever for periodicity in the vicinity of 11 years, except at levels of the general background; that is, well below one standard deviation from the local mean, in a factor-of-three window along $\log$ F. The period near 37.6 years (labeled "Bru" for Brückner) is well off the 33 years that serve Douglass elsewhere as a target for tripling the solar cycle. It happens to be close to twice the (nodal) lunar cycle of 18.61, which dominates tidal ranges in shelf seas. The peak near 57.5 is close to twice the value of 28.3 and is not necessarily in need of separate explanation, therefore. The cycles near 100 average out to 102 , which is sufficiently close to the 101 urged by Douglass to count as confirmation of his assessment.

Of the need to demonstrate the 11-year cycle in the Sequoia series (a task here considered not achieved) Douglass [28, p. 102] wrote as follows: "The question of agreement between the sequoia and the yellow pine is a vital one. Although the sequoias grow in a locality some 450 miles distant, there is a similarity in the rainfall of the two places." From the subsequent text, it is clear that Douglass was puzzled (and perhaps frustrated) by the lack of matching growth patterns in the two regions over much of the common time span. Nevertheless, Douglass concludes [28, p.102] that 
"it seems likely that the sunspot cycle has been operating since 1400 A.D., with some possible interference for a considerable interval about the end of the seventeenth century." The interval in question is presumably the Maunder Minimum of solar activity, which is supposed to have contributed to the Little Ice Age [32].

\section{SOLAR VS TIDAL CYCLES}

Evidently, a crucial goal of Douglass was to find solar cycles within the tree-ring records he studied. He thought that the 500-year tree-ring record at Flagstaff (Arizona) provided a successful demonstration of his expectation. In his conclusions at the end of his first Carnegie treatise [28], Douglass stated the following:

"Practically all the groups of trees investigated show the sunspot cycle or its multiples; the solar cycle becomes more certain and accurate as the area of homogeneous region increases or the time of a tree record extends farther back; this suggests the possibility of determining the climatic and vegetational reaction to the solar cycle in different parts of the world."

In support of his positive assessment concerning the presence of solar cycles, he gives the following table entitled "Changes in the 11-year tree-cycle of Arizona" (his Table 7, p. 108) (remarks here abbreviated):

\begin{tabular}{|c|c|c|}
\hline Years & Period & Remarks \\
\hline $1395-1550$ & 11.3 & Double-crested throughout ... \\
\hline $1550-1595$ & 14.3 & Heavy double crest \\
\hline 1595-1661 & $11.0 \pm 0.5$ & Heavy single crests ... \\
\hline 1661-1677 & 16.0 & (?) Possibly 1 long interval \\
\hline $1677-1770$ & 12.5 & Double crests mostly ... \\
\hline $1770-1793$ & 9.0 & $\begin{array}{l}\text { Sharp single crest continuing } \\
\text { second crest of preceding double }\end{array}$ \\
\hline 1793-1817 & & doubtful \\
\hline $1817-1910$ & 11.6 & $\begin{array}{l}\text { Rather broad, heavy crests, } \\
\text { sometimes double ... }\end{array}$ \\
\hline
\end{tabular}

A multiple Fourier scan of sunspot data (Fig. 2) yields the following sunspot periods for overlapping 50-year intervals, beginning with 1700: 1700-, 11.0; 1725-, 10.6; $1750-, 9.9$; 1775-, 12.8; 1800-, 11.2; 1825-, 10.9; 1850-, $11.0 ; 1875-, 11.6$. The overall average is 11.13 . The list confirms that sunspot periods range widely, and that this range is able, in principle, to accommodate the results given by Douglass. The list does not confirm the particular sequence of periods identified by Douglass.

It seems prudent to remove the "double-crested" cycles from candidacy as evidence for solar activity. The periods $5.65,7.15$ and 6.25 are unlikely of solar origin, and the same is true for 16.0 and for 9.0. Removal of these values leaves two of the numbers in Douglass's table (11.0 and 11.6) as potential solar witnesses. The first is indeed close to the average period of solar activity (Figs. 2, 4). The second occurs within a time period for which actual sunspot observations suggest an average cycle between 10.9 and
11.6. Thus, Douglass's value being at the upper end of this range, it seems somewhat out of line with expectation. Analysis of the relevant section (not shown) yields nothing above the noise level at 11.6. Instead, there is some minor power near 5.7 (one standard deviation above background), whose doubling, in the fashion advocated by Douglass, might be responsible for his finding.

Assuming that the 5.65-year cycle is identical to the 5.7year cycle put forward by Douglass as being dominant (and as verified by analysis of the Flagstaff record, Fig. 5), a link to tidal action (5.8) suggests itself. The same is true for the 6.25 -year period (one third of 18.61 being 6.203) and for the 9.0-year period (one half of the Saros tidal cycle). This approach would leave only the periods of 7.15 and 16.0 without tentative explanations. I suspect that values between 7 and 8 are linked to interference between tidal and solar action, as is true, I think, for values between 20 and 30 (Table 1). The interference periods (referred to as "H-band" in what follows, for the Greek word for seven, and "V-band" for the Latin word for twenty) are simple difference tones of the type $a * b /(a-b)$, where "a" and "b" refer to solar and tidal periods [68].

Table 1. Periods Resulting from Interference Between Solar Cycles (Sol) and Tidal Cycles (Luna). The Two Columns Show Values for the H-Band (Sevens, Perigee Products) and the V-Band (Twenties, Nodal Cycle Products). " $x$ " Marks the Most Common Values for the Second Half of the $20^{\text {th }}$ Century. "D" Marks Two Values Much Mentioned by Douglass [38] $(11.4,7.2)$ and the V-Value Expected if Sol=11.4 Forces the System (29.4). The Gray Area Marks the Most Common Sol Cycles for the Last 300 Years, and the Corresponding $\mathrm{H}$ - and $\mathrm{V}$-Values

\begin{tabular}{|c|c|c|c|}
\hline $\begin{array}{l}\text { luna cycle } \\
\text { sol cycle }\end{array}$ & $\begin{array}{c}\text { perigee } \\
4.424\end{array}$ & $\begin{array}{c}\text { nodal cycl } \\
18.61\end{array}$ & \\
\hline 10.0 & 7.934 & 21.61 & \\
\hline 10.1 & 7.872 & 22.08 & \\
\hline 10.2 & 7.812 & 22.57 & \\
\hline 10.3 & 7.755 & 23.06 & \\
\hline 10.4 & 7.699 & 23.57 & \\
\hline 10.5 & 7.645 & 24.09 & \\
\hline 10.6 & 7.593 & 24.62 & \\
\hline 10.7 & 7.543 & 25.17 & $x$ \\
\hline 10.8 & 7.494 & 25.73 & $\mathbf{x}$ \\
\hline 10.9 & 7.446 & 26.30 & \\
\hline 11.0 & 7.400 & 26.89 & \\
\hline 11.1 & 7.356 & 27.50 & \\
\hline 11.2 & 7.312 & 28.12 & \\
\hline 11.3 & 7.270 & 28.76 & \\
\hline 11.4 & 7.230 & 29.42 & D \\
\hline
\end{tabular}

According to the interference scheme of Table 1, a treering period of 7.2 supports the presence of a solar cycle of length 11.4, while a tree-ring period of 8.0 (one half of 16) would support a solar cycle of 9.9. A tree-ring cycle of 23.7 (as seen in the Flagstaff data, Fig. 5) would support the presence of a solar cycle of 10.43, as mentioned above, and a tree-ring period of 28.3 (as seen in the Sequoia data, Fig. 6) would support the presence of a solar activity period of 11.2 years.

In this context, Douglass's statement regarding the Flagstaff series, that "the interval from 1830 to the present time [1910] divides also extremely well on a 21.0 period, 
and fairly well in one of 7.3 years" is of interest. It could be interpreted as implying the presence of a 10.5-year cycle (doubled to make 21) and an interference period supported by a solar cycle of 11.2 (Table $\mathbf{1}$ ).

To answer potential criticism that anything can be "explained" when allowing interference patterns to enter the argument (a point expressed to me in discussion), I should point out that the scheme in Table $\mathbf{1}$ is very specific: each value in the twenties implies a unique value in the range 7 to 8 , and both values together imply a unique solar period. Obviously, the tidal periods are given within narrow limits $(18.61,4.424,5.80)$. Even the phases are known precisely for the last several centuries. Thus, there is much opportunity for statistical rigor, once there is interest in pursuing the matter. In fact, there is an opportunity to model that portion of the climate record that is deterministic (which is on the order of $15 \%$ of the total, according to Douglass), with some benefits in regard to the task of identifying mechanisms. Such a task calls for special skills in meteorology and statistics, and is well beyond the purely observational approach that guides the effort here presented.

It appears to me that Douglass discovered tidal information within the growth rings of trees in the West, without being aware of the fact. The implication is that ocean oscillations are involved in controlling precipitation patterns in western North America. If tidal activity is important in such oscillations, we should see their effects in the relevant periodograms. I offer three tests of this notion in what follows: an analysis of ENSO-related series (one based on historical data, the other on tree-rings; Fig. 7) and an analysis of data concerning the North Pacific Decadal Oscillation (Fig. 8). For database, I use the tables presented by Quinn [53], by Stahle et al. [59] and by Mantua et al. [69] and the corresponding web site at Washington University, giving PDO information.
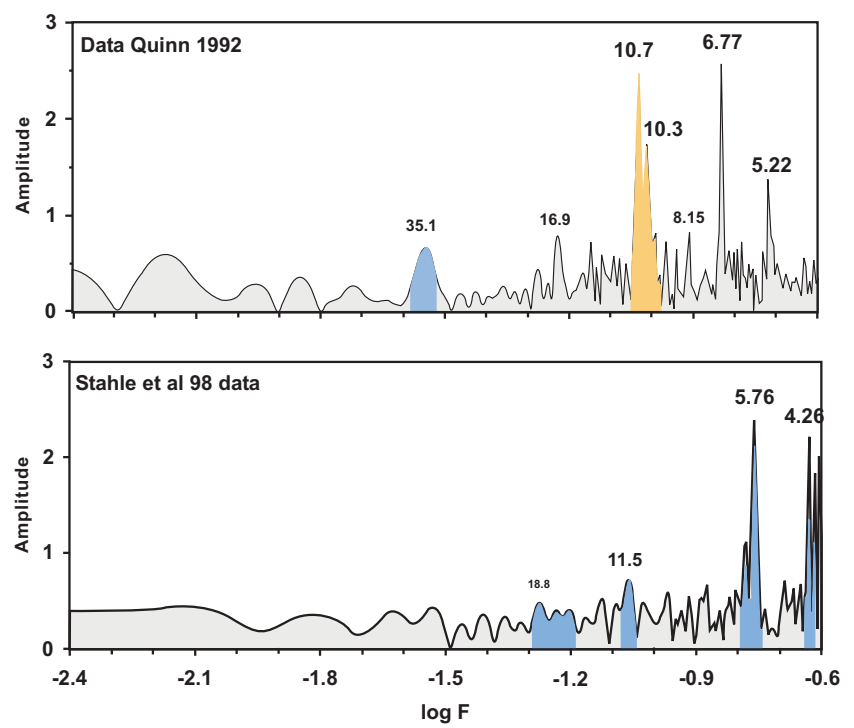

Fig. (7). Periodograms of ENSO-related reconstructions. Upper: ENSO history based on historical information. Lower: ENSO history inferred from tree-ring data. Sources: Quinn [53] and Stahle et al. [59]. Orange: here assumed sun-related. Blue: here assumed tide-related.
Quinn's tabulation of historical ENSO events (his Table 6.1) is given in the book "El Niño," edited by Diaz and Markgraf [12], which has a number of instructive articles on the paleoclimatic aspects of the Southern Oscillation. Quinn's entries on "moderate," "strong," or "very strong" events were indexed $(2,5$, and 7$)$, with plus and minus sign interpreted as adding or subtracting one unit in the index. The first year listed is taken as the time of the event. Each entry was then distributed to adjacent years: one fourth of the value for the year preceding and the year following, one half of the value for the "event" year. The time span covered by Quinn's list is 494 years, ending in 1990. Results of the Fourier scan (Fig. 7, upper panel) document the presence of two strong periods between 10 and 11 years, centered on 10.5 , and with peaks for 10.7 and 10.3. These results suggest, therefore, a role for solar activity in producing the ENSO history reconstructed by Quinn. A check on coincidence of phase of sunspots and reconstruction (not shown) proved inconclusive, though. The most remarkable peak in the periodogram is at 6.77 , a line whose origin is obscure. (It is present at 6.6 in the meteorological SOI record; but there is nothing of note near 11 in that record, as I ascertained.) The peak at 5.22 is here taken as a Douglasstype halving of solar power.

In contrast to Quinn's record, the ENSO reconstruction from tree-ring patterns in the southwestern parts of North America by Stahle et al. [59] has no information at all on the influence of solar cycles in the history of the Southern Oscillation (Fig. 7, lower panel). There is then, from comparing the two periodograms, little or no correlation between the history reconstructed by Quinn [53], and the one extracted from tree-ring information by Stahle et al. [59]. There are a number of possible explanations for this puzzling situation, as follows. (1) Either the reconstruction of Quinn or the one of Stahle et al. does not reflect ENSO history, or neither one of the reconstructions does so; (2) Quinn's reconstruction has merit, but the ENSO variation does not influence tree-rings in the southwestern parts of North America; (3) the analysis here presented is irrelevant to the problem of correlation between the two reconstructions.

Of these various possibilities, it seems parsimonious to contemplate the conclusion that Quinn's reconstruction (which uses Nile flood data) may be contaminated by solardriven precipitation in North Africa, while the tree-ring reconstructions may or may not track the history of the ENSO phenomenon, but are surely linked to ocean information. While the historical ENSO series compiled by Quinn appears dominated by solar information, the reconstruction by Stahle et al. [59], with its strong lines near 5.8 and 4.3 seems dominated by tidal-range cycles (at 5.8 and 4.4). If so, the modest peak at 11.5 is of tidal origin as well: it represents a doubling of the dominant 5.76-year line.

To further test the relevance of Quinn's reconstruction to what is happening in the equatorial Pacific, I have analyzed coral data (oxygen isotopes) published by Dunbar et al. [70] and by Cobb et al. [71], and available from the World Data Center (NOAA Paleoclimate Program) in Boulder, Colorado. The data of Dunbar et al., from the eastern equatorial Pacific span the time between about 1600 to 1950 . They show a remarkable change, in the time domain, in the nature of fluctuations early in the $19^{\text {th }}$ century. I have analyzed the 


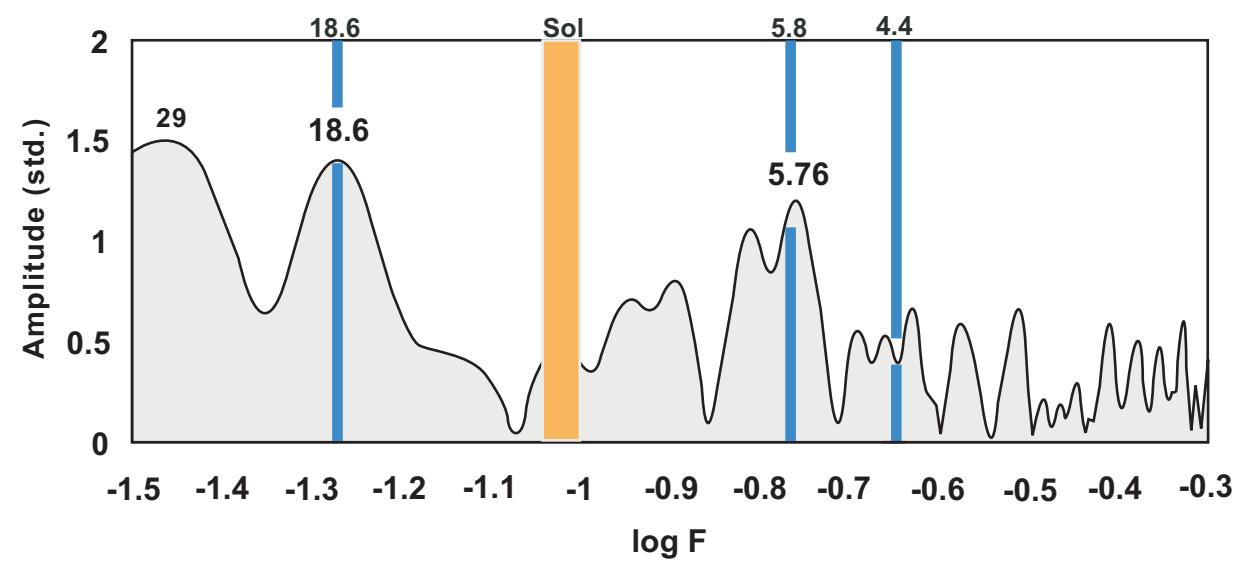

Fig. (8). Periodogram for the Pacific Decadal Oscillation in the $20^{\text {th }}$ century. Source of data: Mantua et al. [69], Zhang et al. [72], URL: $\mathrm{http}: / / w w w . a t m o s . w a s h i n g t o n . e d u$. The marked lines $(18.6,5.8,4.4)$ are those expected for tidal activity.

sections before and after 1820 separately, therefore. Before 1820 , the dominant cycles are near 42,59 and 5.8 years. The latter presumably qualifies as a match to the 5.7-year Douglass cycle.

There is no power at all between 10 and 11 years in the spectrum, or anywhere near 11 years. However, in the series from 1820 to 1953 , there is a strong period at 10.8 , close to the dominant sunspot cycle. The other two dominant cycles in this section are centered at 15.8 and 8.0, the latter being presumably the driving period and the longer one the double. While the presence of the 10.8 cycle suggests that the sun's variation cannot be discounted entirely as an influence in ENSO history, it is unlikely to provide confirmation for Quinn's results, being prominent only relatively recently. It is interesting, however, that the variability of oxygen isotope values over the entire time span, within an eleven-year gliding window, has strong cycles at $66,50.5,34$ and 26 , which happens to correspond to $1 / 3,1 / 4,1 / 6$ and 1/8 of a period near 200 years. Such a period has been proposed as a solar cycle, and is seen in the Schove aurora series [52], as mentioned.

The data of Cobb et al. [71], which stem from the western edge of the eastern equatorial Pacific (Palmyra), were reduced to six non-overlapping sections of annual variation of the $\delta^{18} \mathrm{O}$ series obtained from various corals. None of these sections (centered in the $10^{\text {th }}$, the $12^{\text {th }}$, the $14^{\text {th }}$, the $15^{\text {th }}$, the $17^{\text {th }}$, and the $20^{\text {th }}$ centuries) show any periodicity between 10 and 11 years. The most common periods seen are near five years. The Douglass cycle appears once, in the $20^{\text {th }}$ century (at 5.66). Prominent lines also appear near 7.7 $\left(10^{\text {th }}\right.$ century) and $7.9\left(15^{\text {th }}\right.$ century), periods that are reminiscent of a strong period near 7.75 present in the North Atlantic Oscillation [68].

On the whole, periods found in the coral data of the equatorial Pacific seem more compatible with the results of Stahle et al. [59] than those of Quinn [53].

For the regions in the West that are strongly influenced by ocean oscillations in the North Pacific, the spectrum of the Pacific Decadal Oscillation $[69,72]$ is of interest. Like the spectrum of the ENSO reconstruction of Stahle et al. [59] this spectrum has a strong peak at 5.76 (the strongest within the band of periods less than 10 years long). Also, and unmistakably, the PDO spectrum contains the tidal cycle of
18.6 (nodal lunar cycle, describing the line-up of Sun, Earth, and Moon) $[61,73,74]$. In contrast to this strong presence of a lunar signal, there is but negligible power at the solar periods near 11 years.

While we cannot be certain that the peak at 5.76 in the PDO is identical to the Douglass cycle near 5.7, it would seem to be a reasonable inference. The step from there to the 5.8 tidal interference cycle is a small one.

\section{CONCLUSIONS}

A.E. Douglass, in a 500-year "yellow pine" growth series from Flagstaff, Arizona, discovered an important growth rhythm with a period near 5.7 years [28]. The origin of this rhythm is still obscure, almost a century later. Douglass interpreted it as one-half of a solar cycle at 11.4 years. Since such a cycle is not evident in the available data on solar variability, some other explanation seems called for. I suggest tidal activity, based on several lines of evidence (mainly, the closeness of 5.7 to the tidal interference cycle of 5.80 , and the demonstrable presence of tidal information in the PDO).

Whether this re-interpretation is accepted or not, Douglass own assessment does seem quite questionable. Here is his summary [28, p.98]:

"With the understanding that the study of cycles is not yet complete, it may be stated at once that the more conspicuous and general cycles at once apparent in the trees are directly related to the solar period. They are as follows :

5 to 6 years approximate half sunspot period.

10 to 13 “ " full “ “

21 to 24 “ " double “ “

32 to 35 “ " triple “ “

100 to 105 “ " triple-triple “ “

Douglass here assigns meaning to the most conspicuous periods he discovered using his novel periodograph, all in terms of solar cycles. Given the lack of support from relevant solar activity variations, and from the properties of the series he generated, I find it difficult to accept his conclusions, although whole-number multiples of solar 
cycles cannot be excluded as important factors in shaping the chaotic fluctuations of large-scale climate patterns.

My re-assessment of his solar-cycle findings does not in any way impact the merits of Douglass's fundamental discoveries, which are reflected in the following summary [28, p.98]:

\section{"It has already been stated that three characteristics were observed in the curves of tree-growth: (1) correlation with rainfall; (2) correlation with sunspots; (3) general periodic variation. In the first and second of these the trees are compared directly with existing records, but in the third the tree record is available over hundreds and even thousands of years during which no human observations were recorded. Thus, if previous inferences are correct, the trees may reasonably be expected to give us some knowledge of prehistoric conditions.}

Douglass had no illusions about the difficulties he faced for finding acceptance of his arguments regarding the presence of solar cycles in the tree rings he studied [ibid., p.81]:

“... in general the great weight of opinion has been against a traceable effect of solar activity on weather or climate."

Douglass's statement still rings true. In contrast, regarding any traceable tidal effects, there does not seem to be much evidence for any opinion at all: so far, the problem does not appear to have risen to the level of warranting discussion.

\section{ACKNOWLEDGEMENTS}

I thank Dr. Connie Millar for inviting me to speak on Douglass's research on cycles in tree rings at the Mountain Climate Meeting she convened at the H.J. Andrews Forest Research facility in Oregon, in June 2010, and I thank the participants for their interest and for discussions.

\section{REFERENCES}

[1] Fritts HC. Tree rings and climate. London and New York: Academic Press 1976.

[2] Webb GE. Tree rings and telescopes - the scientific career of A.E. Douglass. Tucson: The University of Arizona Press 1983.

[3] Baillie MGL. A slice through time: dendrochronology and precision dating. Oxford: Routledge 1995.

[4] Douglass AE. Dating our prehistoric ruins. Nat Hist 1921; 21: 2730.

[5] Meko D, Stockton CW, Boggess, WR. The tree-ring record of severe sustained drought. Water Resour Bull 1995; 31: 789-801.

[6] Woodhouse CA, Overpeck JT. 2000 years of drought variability in the central United States. Bull Am Meteor Soc 1998; 79: 2693-714.

[7] Cook ER, Woodhouse CA, Eakin CM, Meko DM, Stahle DW. Long-term aridity changes in the western United States. Science 2004; 306: 1015-8.

[8] Ladurie EL. Times of feast, times of famine: a history of climate since the year 1000. (Transl. B. Bray.) Garden City: Doubleday 1971.

[9] Rotberg RI, Rabb TK. Climate and history. Princeton New Jersey: Princeton University Press 1981.

[10] Lamb HH. Climate, history and the modern world. London and New York: Methuen 1982.

[11] Grove JM. The Little Ice Age. New York: Methuen 1988
[12] Diaz HF, Markgraf V., Eds. El Niño: historical and paleoclimatic aspects of the Southern Oscillation. Cambridge: Cambridge University Press 1992.

[13] Hughes MK, Diaz HF. Was there a medieval warm period, and If so, where and when. Clim Change 1994; 26: 109-42.

[14] Hsủ KJ. Klima macht Geschichte. [Climate makes history] Zurich: Orell Füssli 2000.

[15] Fagan B. The great warming-climate change and the rise and fall of civilizations. New York: Bloomsbury Press 2008.

[16] Schulman E. Tree rings and runoff in the South Platte River basin. Tree-Ring Bull 1945; 11: 18-24.

[17] Stockton CW. Long-term streamflow reconstructions in the upper Colorado river basin using tree rings. In: Clyde GC, Falkenborg DH, Riley JP, Eds. Colorado river basin modeling studies. Logan Utah: Utah State University 1976; pp. 401-41.

[18] Meko D, Graybill DA. Tree-ring reconstructions of Upper Gila River discharge. Water Resour Bull 1995; 31: 605-15.

[19] Woodhouse CA. A tree-ring reconstruction of streamflow for the Colorado Front Range. J Am Water Resour Ass 2001; 37: 561-9.

[20] Meko DM, Woodhouse CA, Baisan CA, et al. Medieval drought in the upper Colorado river basin. Geophys Res Lett 2007; 34: L10705.

[21] Intergovernmental Panel on Climate Change. In: Houghton JT, Ding Y, Griggs DJ, et al., Eds. Climate Change 2001: The Scientific Basis. Contribution of Working Group I to the Third Assessment Report of the Intergovernmental Panel on Climate Change. Cambridge: Cambridge University Press 2001.

[22] Intergovernmental Panel on Climate Change. In: Bernstein L, Bosch P, Canziani O, et al., Eds. Climate Change, Synthesis Report (Fourth Assessment), IPCC Plenary XXVII, Valencia 2007.

[23] Mann ME, Kump LR. Dire prediction-understanding global warming. New York: Dorling Kindersley 2009.

[24] Douglass AE. A method of estimating rainfall by the growth of trees. In: E. Huntington Ed. The climatic factor. Washington: Carnegie Institution 1914; pp. 101-21.

[25] Douglass AE. Crossdating in dendrochronology. J Forestry 1941; 39: 825-31.

[26] Hughes MK, Kelly PM, Pilcher JR, LaMarche VC, Eds. Climate from tree rings. Cambridge London New York: Cambridge University Press 1982.

[27] Cook ER, Kairiukstis LA, Eds. Methods of dendrochronology: applications in environmental sciences. Dordrecht: Kluwer Academic 1990.

[28] Douglass AE. Climatic cycles and tree-growth. Washington: Carnegie Institution 1919; vol. I.

[29] Douglass AE. Climatic cycles and tree-growth. Washington: Carnegie Institution 1928; vol. II.

[30] Douglass AE. Climatic cycles and tree-growth. Washington: Carnegie Institution 1936; vol. III.

[31] Burroughs WJ. Weather cycles: real or imaginary? Cambridge: Cambridge University Press 1972.

[32] Eddy JA. The maunder minimum. Science 1976; 192: 1189-202.

[33] Mass C, Schneider SH. Statistical evidence on the influence of sunspots and volcanic dust on long-term temperature records. J Atmos Sci 1977; 34: 1995-2004.

[34] Currie RG. Distribution of solar cycle signal in surface air temperature over North America. J Geophys Res 1979; 84: 753-61.

[35] Mitchell JM Jr., Stockton CW, Meko DM. Evidence of a 22-year rhythm of drought in the western United States related to the Hale solar cycle since the 17th century. In: McCormac BM, Seliga TA, Eds. Solar terrestrial influences on weather and climate. Dordrecht: Reidel 1979; pp. 125-43.

[36] Stuiver M, Quay PD. Changes in atmospheric carbon-14 attributed to a variable sun. Science $1980 ; 207: 11-9$.

[37] Schuurmans CJE. Solar activity and climate. In: Berger A, Ed. Climatic variation and variability: facts and theories. Dordrecht: Reidel 1981; pp. 559-75.

[38] Pollack JB. Solar, astronomical and atmospheric effects on climate In: Berger WH, Crowell JC, Eds. Climate in Earth history. Studies in Geophysics. Washington D.C.: National Academy Press 1982.

[39] Schönwiese CD, Ullrich R, Beck F, Rapp J. Solar signals in global climate change. Clim Change 1994; 27: 259-81.

[40] Lean J, Rind D. The sun and climate. Consequences 1996; 2: 2736 . 
[41] Cook ER, Meko DM, Stockton CW. A new assessment of possible solar and lunar forcing of the bidecadal drought rhythm in the western United States. J Clim 1997; 10: 1343-56.

[42] Hoyt DV, Schatten KH. The role of the sun in climate change. Oxford: Oxford University Press 1997.

[43] Haigh JD. Modelling the impact of solar variability on climate. J Atmos Solar-Terr Phys 1999; 61: 63-72.

[44] Beer J, Mende W, Stellmacher R. The role of the sun in climate forcing. Quat Sci Rev 2000; 19: 403-15.

[45] Haigh JD. The effects of solar variability on the Earth's climate. Phil Trans Roy Soc Lond 2003; A 361: 95-111.

[46] Solanki SK. Solar variability and climate change: is there a link? Astron. Geophys 2002; 43: 5.09-5.13.

[47] Pap JM, Fox P, Eds. Solar variability and its effects on climate. Am. Geophys Union Geophys Monogr 2004; 141: 1-366.

[48] Bard E, Frank M. Climate change and solar variability: what's new under the Sun? Earth Planet Sci Lett 2006; 248: 1-14.

[49] Foukal P, Fröhlich C, Spruit H, Wigley TML. Variations in solar luminosity and their effect on the Earth's climate. Nature 2006; 443; 161-6.

[50] Laut P. Solar activity and terrestrial climate: an analysis of some purported correlations. J Atmos Solar-Terr Phys 2003; 65: 801-12.

[51] North GR, Wu Q, Stevens MJ. Detecting the 11-year solar cycle in the surface temperature field. AGU Geophys Monogr 2004; 141: 251-9.

[52] Schove DJ. Solar cycles and equatorial climates. Geol Rdsch 1964; 54: 448-77.

[53] Quinn WH. A study of Southern Oscillation-related climatic activity for A.D. 622-1900 incorporating Nile River flood data. In: Diaz HF, Markgraf V, Eds. El Niño: historical and paleoclimatic aspects of the Southern Oscillation. Cambridge: Cambridge University Press 1992.

[54] Stockton CW, Mitchell JM, Meko DM. Tree-ring evidence of a relationship between drought occurrence in the western United States and the Hale sunspot cycle. In: Lawson M, Baker ME, Eds. The Great Plains, perspectives and prospects. Lincoln: University of Nebraska Press 1981; pp. 83-110.

[55] Currie RG. Evidence for 18.6-year MN signal in temperature and drought conditions in North America since 1800 AD. J Geophys Res 1981; 86: 1105-64.

[56] Currie RG. Luni-solar 18.6 and solar cycle 10-11 year signals in USA air temperature records. Intern J Clim 1993; 13: 31-50.

[57] Cayan DR, Peterson DH. The influence of North Pacific atmospheric circulation on streamflow in the West. In: Peterson DH, Ed. Aspects of climate variability in the Pacific and the western Americas. AGU Geophys Monogr 1989; 55: 375-97.
[58] Cayan DR, Dettinger MD, Diaz HF, Graham NE. Decadal variability of precipitation over western North America. J Clim 1998; 11:3148-66.

[59] Stahle DW, D'Arrigo RD, Krusic PJ, et al. Experimental dendroclimatic reconstruction of the Southern Oscillation. Bull Amer Meteor Soc 1998; 79: 2137-52.

[60] McCabe GJ, Palecki MA, Betancourt JL. Pacific and Atlantic Ocean influences on multidecadal drought frequency in the United States. Proc Nat Acad Sci USA 2004; 101: 4137-41.

[61] Yasuda I. The 18.6-year period moon-tidal cycle in Pacific Decadal Oscillation reconstructed from tree-rings in western North America. Geophys Res Lett 2009; 36: L05605.

[62] Hurrell JW, Kushnir Y, Ottersen G, Visbeck M, Eds. The North Atlantic Oscillation, climatic significance and environmental impact. Am Geophys Union Geophys Monogr 2003; 134: 1-279.

[63] Pittock B. Can solar variability explain variations in the Earth's climate? An editorial comment. Clim Change 2009; 96: 483-7.

[64] Duffy PB, Santer BD, Wigley, TML. Solar variability does not explain late-20th-century warming. Physics Today 2009; 62: 48-9.

[65] Feulner G, Rahmstorf, S. On the effect of a new grand minimum of solar activity on the future climate on Earth. Geophys Res Lett 2010; 37: L05707 1-5.

[66] Gleissberg W. Ascent and descent in the eighty-year cycles of solar activity. J Brit Astron Soc 1966; 76: 265-70.

[67] Stehr N, von Storch H, Eds. Eduard Brückner - the sources and consequences of climate change and climate variability in historical times. Dordrecht: Kluwer Academic 2000.

[68] Berger WH. Solar modulation of the North Atlantic Oscillation: Assisted by the tides?, Quat Intern 2008; 188: 24-30.

[69] Mantua N, Hare SR, Zhang Y, Wallace JM, Francis RC. A Pacific interdecadal climate oscillation with impacts on salmon production. Bull Am Meteor Soc 1997; 78: 1069-79.

[70] Dunbar RB, Wellington GM, Colgan MW, Glynn PW. Eastern Pacific sea surface temperature since 1600 A.D.: the $\delta^{18} \mathrm{O}$ record of climate variability in Galapagos corals. Paleoceanography 1994; 9 : 291-315.

[71] Cobb KM, Charles CD, Cheng H, Edwards RL. El Niño/Southern Oscillation and tropical Pacific climate during the last millennium. Nature 2003; 424(6946): 271-6.

[72] Zhang Y, Wallace JM, Battisti DS. ENSO-like interdecadal variability: 1900-93. J Clim 1997; 10: 1004-20.

[73] Berger WH. On glacier retreat and drought cycles in the Rocky Mountains of Montana and Canada. Scripps Inst. Ocean. Tech Rpt 2009, UCSD. http://escholarship.org/uc/item/4485x93s

[74] Berger WH. On glacier retreat and drought cycles in Montana and Canada. Quat Intern 2010; 215: 27-33. 